\title{
Diagnosis System of Toddler Diseases Using Forward Chaining and Case-Based Reasoning
}

\author{
Indah Werdiningsih ${ }^{1}$, Aisyah Shofiyyah $\mathrm{Asma}^{2}$, Rimuljo Hendradi ${ }^{3}, \mathrm{Kartono}^{4}$, Purbandini ${ }^{5}$, \\ Barry Nuqoba ${ }^{6}$, Elly Anna ${ }^{7}$ \\ \{indah-w@fst.unair.ac.id ${ }^{1}$, aisyah.shofiyah-13@fst.unair.ac.id², rimuljo-h@fst.unair.ac.id $\left.{ }^{3}\right\}$ \\ Study Program of Information System, Faculty of Science and Technology, Airlangga University ${ }^{123456}$, \\ Study Program of Statistic, Faculty of Science and Technology, Airlangga University ${ }^{7}$
}

\begin{abstract}
Toddlers are children aged 12-36 months. This study aims to diagnose toddler diseases using forward chaining and Case-Based Reasoning $(C B R)$. There are 16 types of toddler diseases. This study consist of two steps, i.e., diagnosis using forward chaining and diagnosis using CBR. Diagnosis using forward chaining generated 18 rules. These rules were used to determine toddler diseases type, and diagnosis using CBR focused on three types of CBR calculations, i.e., Nearest Neighbour Similarity (NNS), Minkowsky Distance Similarity (MDS), and Euclidean Distance Similarity (EDS). The results of system testing using 600 data, the accuracy of diagnosis were $82 \%$ and $90 \%$, using forward chaining and CBR respectively. Based on these results, diagnosis using CBR was better than forward chaining, because CBR justified the data that were considered wrong, to be repaired by an expert and then made them as new cases.
\end{abstract}

Keywords: case-based reasoning, forward chaining, nearest neighbour similarity, minkowsky distance similarity, euclidean distance similarity.

\section{Introduction}

The toddler age which ranged from 12 to 36 months was very susceptible to disease[1]. More than 400 children died every day in Indonesia; it was due to diseases that were actually easy to be prevented and treated such as pneumonia and diarrhea[2]. Toddler mortality data in Indonesia shows that toddler mortality was approximately $65 / 1,000$ births[3]. This was in contrary with the statement of the World Health Organization (WHO) in 1946, which mentioned that all children had the right for health, so that they have the opportunity to become world citizens[1].

The book entitled Manajemen Terpadu Balita Sakit Berbasis Masyarakat (MTBS-M) was issued by WHO in collaboration with the Departemen Kesehatan Republik Indonesia (Depkes RI) and the Ikatan Dokter Indonesia (IDI). MTBS-M aims to improve access to sick children services in the community on areas that are difficult to be accessed by health services[4]. MTBS-M contains health assistance, toddler care at home, community training to do simple treatment for young babies and sick toddlers to reduce toddler mortality[4].

Decision support systems (DSS) are interactive computer-based systems that help decision makers by utilizing data and models to solve unstructured problems[5], [6]. Expert systems with forward chaining methods have been used in several studies including Automated Scheduling System for Thesis and Project Presentation Using Forward Chaining Method With

ICCSET 2018, October 25-26, Kudus, Indonesia

Copyright (C) 2018 EAI

DOI 10.4108/eai.24-10-2018.2280501 
Dynamic Allocation Resources[7]. Implementation of forward Chaining Method for Early Detection of Diabetes Mellitus[8], Application of Expert System for Diagnosing Infectious Diseases for Toddlers Using Forward Chaining Method[9], and expert system supporting an early prediction of the bronchol pulmonary dysplasia[10].

CBR is a problem-solving method that can be reused in similar cases to find solutions for new problems by referring to the base case[11]. The CBR method has been widely developed in the medical world. The diagnosis reasoning in the medical field using CBR method was using pattern matching type, the point was treated using case-based reasoning process based on the experience of previous patients[12]. The CBR process has four-steps, where the process made CBR easy to update its knowledge base so that it can solve complex and unstructured problems [11].

There were several studies on CBR, one of them was the CBR for Diagnosis of Heart Disease [13]. In this study, three types of classification methods were used to diagnose six types of heart disease. The classification method used was Nearest Neighbor Similarity (NNS), Minkowski Distance Similarity (MDS) and Euclidean Distance Similarity (EDS), with accuracy rates of $86.21 \%, 100 \%$, and $94.83 \%$ respectively. CBR can improve the accuracy rate for diagnosing diseases.

Based on the description above, this study would apply forward chaining and CBR to diagnose toddler diseases based on DSS. This study was expected to be able to appropriately diagnose cases of toddler diseases and improve the accuracy of system classification.

\section{Methodology}

\subsection{Forward Chaining}

The following were a general description of the expert system application:

1) Input, questions that appear in the expert system application.

2) Knowledge base (knowledge domain), knowledge of diseases classification based on the MTBS used as rule-based.

3) Working memory, facts entered by the user to the expert system application.

4) Inference Engine, the process of matching the facts that exist in working memory with the knowledge domain, to conclude the problem at hand.

5) Classification of diseases, the conclusion of the expert system diagnosis process

\subsection{Case Based Reasoning (CBR)}

CBR is a major paradigm in reasoning that can solve new problems by paying attention to the similarity of problem-solving from previous problems.

\subsection{Steps of CBR}

Steps of CBR were case base determination, expert weighting, local similarity, confidence level, global similarity, and selection of the highest value. 


\subsubsection{Case base determination}

Case base was used for storage. Each stored case was divided into several main parts, i.e., toddler identity, disease symptom, and disease diagnosis.

\subsubsection{Expert weighting}

The purpose of parameter weighting was to determine the influence of each parameter to other parameters [12], [13]. Parameter weighting was carried out by experts and assisted by statistical calculations.

\subsubsection{Local Similarity}

The local similarity was the proximity between local attributes or the same attributes[13]. The local similarity was done by defining the proximity between attribute values. Local similarity calculations were calculated based on data type, the calculation for numeric data types shown in equations (1) and (2). Local similarity formula for numeric data types:

Notation:

$$
f(s, t)=1-\frac{|s-t|}{R}
$$

$\mathrm{s}$, t: Attribute value to be compared

$\mathrm{R}$ : Attribute value range

Local similarity formula for boolean data types:

Notation:

$$
f(s, t)=\left\{\begin{array}{l}
1, \text { if } s=t \\
0, \text { others }
\end{array}\right.
$$

$\mathrm{s}, \mathrm{t} \in\{$ true,false $\}$

\subsubsection{Confidence level}

The confidence level was divided into two levels, i.e. level of expert confidence, and level of confidence in a new case to the previous case. The level of expert confidence was calculated based on the disease category that was determined by experts based on the symptoms and risk factors suffered by the patient. The confidence level in a new case to the previous case was calculated by equation (3).

$$
\mu_{(T, S)}=\frac{J(S, T)}{J(S)}
$$

Notation: 
$\mu_{(T, S)} \quad$ : Confidence level between $\mathrm{T}$ case (new case) and $\mathrm{S}$ (previouscase)

$\mathrm{J}(\mathrm{S}, \mathrm{T})$ : Number of symptoms in new cases that appear in the symptoms of the previous case.

$\mathrm{J}(\mathrm{S}) \quad$ : Number of symptoms in the base case.

\subsubsection{Global Similarity}

Global similarity aims to look for similarity between attributes in all existing variables. The algorithms used in the global similarity process were Nearest Neighbor Similarity, Minkowski Distance Similarity, and Euclidean Distance Similarity.

1. Nearest Neighbor Similarity:

$$
\operatorname{SimNN}(T, S)=\frac{\sum_{i=1}^{n}\left(f_{i}\left(S_{i}, T_{i}\right)\left(w_{i, p(s)}\right)\right)}{\sum_{i=1}^{n}\left(w_{i, p(s)}\right)} * P(S) * \frac{J\left(S_{i}, T_{i}\right)}{J\left(T_{i}\right)}
$$

Notation:

Simon $(\mathrm{S}, \mathrm{T}) \quad$ : Global Similarity between $\mathrm{T}$ case and $\mathrm{S}$ (source case)

$N \quad$ : Number of features available

$f_{i}\left(S_{i}, T_{i}\right) \quad:$ The same the $\mathrm{i}^{\text {th }}$ feature from source case and target case /

$S_{i} \quad$ function of local similarity

$S_{i} \quad:$ The $\mathrm{i}^{\text {th }}$ featurein source case

$T_{i} \quad:$ The $\mathrm{i}^{\text {th }}$ feature in target case

$w_{i, p(s)} \quad:$ Weighting value of $\mathrm{i}^{\text {th }}$ feature in diseases from source case

$P(S) \quad:$ Percentage of expert confidence in a case in the source case

$J\left(S_{i}, T_{i}\right) \quad:$ Number of features in target case that appear in the features of

$J\left(T_{i}\right) \quad:$ The number of features was in target case

2. Minkowsky Distance Similarity:

$$
\operatorname{SimMD}(S, T)=\left[\frac{\sum_{i=1}^{n}\left(w_{i,(p(s))}\right)^{3} *\left|f_{i}\left(S_{i} T_{i}\right)\right|^{3}}{\sum_{i=1}^{n}\left(w_{i, p(s)}\right)^{3}}\right]^{\frac{1}{3}} * P(S) * \frac{*\left(S_{i,}, T_{i}\right)}{J\left(T_{i}\right)}
$$

Notation:

$\operatorname{SimMD}(\mathrm{S}, \mathrm{T}) \quad$ : Global Similarity between $\mathrm{T}$ (target case) and $\mathrm{S}$ (source case)

$R \quad$ : Minkowski factor (positive integer) $(\mathrm{r}=3)$

3. Euclidean Distance Similarity:

$$
\operatorname{SimED}(S, T)=\left[\frac{\sum_{i=1}^{n}\left(w_{i,(p(s))}\right)^{2} *\left|f_{i}\left(S_{i}, T_{i}\right)\right|^{2}}{\sum_{i=1}^{n}\left(w_{i, p(s)}\right)^{2}}\right]^{\frac{1}{2}} * P(S) * \frac{J\left(S_{\left.i, T_{i}\right)}\right.}{J\left(T_{i}\right)}
$$

Notation:

SimED (S,T) : Global Similarity between $\mathrm{T}$ (target case) and S (source case) 


\subsubsection{Selection of The Highest Value}

Selection of the highest value was the process of selecting cases that had been stored in case base to be selected as a solution, where the data had the highest level of similarity[13].

\section{Result}

\subsection{Data and Information Collection}

Data and information collection were done by interview, literature study, and data collection. Interview was done with one of the medical staff in a hospital in Surabaya. Interview result was variables that influence toddler diseases. These variables were given weight to assess severity of the diseases. Literature study was done by studying matters related to the method used, and finding out the variables that influence the diagnosis of toddlers.

Data collection was done by reading the patient's medical record data. The number of collected data was 600 data. The data was divided into training and testing data. 450 training data and 150 testing data.

\subsection{Data and Information Management}

Data and information obtained were analyzed to build a system that was matching with the user needs. Data and information management consist of two steps, i.e. forward chaining and CBR.

\subsubsection{Management of Forward Chaining}

The results of literature study were the steps of forward chaining method. Code of complaints were $\mathrm{K} 1=$ cough, $\mathrm{K} 2$ = Diarrhea, and $\mathrm{K} 3=$ Fever. Data and information about symptoms fact, diseases and complaints experienced by toddler were shown in Table 1 and Table 2.

1. Rule-based generation

Based on the facts obtained, the rule was generated. Eighteen rules were generated based on diseases. The rules generated could be seen in Table 3 .

Table 1.Symptoms Variable.

\begin{tabular}{|c|c|c|c|}
\hline Code & Symptoms & Code & Symptoms \\
\hline G1 & Child cannot drink or suckle & G14 & Diarrhea of 14 days or more \\
\hline G2 & Vomited & G15 & Blood in the feces \\
\hline G3 & Seizures & G16 & Fever \\
\hline G4 & Children appear unconscious & G17 & $\begin{array}{l}\text { Child can not bow down until } \\
\text { chin reaches chest }\end{array}$ \\
\hline G5 & Quick breathing & G18 & Rash on skin \\
\hline G6 & chest wall pulled inside & G19 & Cough, cold or red eyes \\
\hline G7 & Stridor & G20 & $\begin{array}{l}\text { Turbidity of the cornea of the } \\
\text { eyes }\end{array}$ \\
\hline G8 & liquid or mushy defecation & G21 & Wounds in the mouth \\
\hline
\end{tabular}




\begin{tabular}{clll} 
G9 & Hollowed eyes & G22 & Purulent eyes \\
G10 & Puncture of abdominal skin slowly returned & G23 & Fever of 2 - 7 days \\
G11 & Fussy / irritable & G24 & $\begin{array}{l}\text { Continuous Fever with suddenly } \\
\text { high temperature }\end{array}$ \\
G12 & Thirsty & G25 & Diarrhea \\
G13 & Gently drinking & G26 & Cough/cold \\
\hline
\end{tabular}

Table 2.Diseases Table

\begin{tabular}{clcl}
\hline Code & Classification of disease & Code & \multicolumn{1}{c}{ Classification of disease } \\
\hline P1 & Common risk sign & P10 & Dysentery \\
P2 & Cough & P11 & Fever \\
P3 & Pneumonia & P12 & Fever with common risk sign \\
P4 & Severe Pneumonia & P13 & Measles \\
P5 & Diarrhea & P14 & Measles with severe complication \\
P6 & Mild Dehydration Diarrhea & P15 & Measles with complication \\
P7 & Severe Dehydration Diarrhea & P16 & fever may be DBD \\
P8 & Persistent diarrhea & P17 & DBD \\
P9 & Severe persistent diarrhea & P18 & Fever is not DBD \\
\hline
\end{tabular}

Table 3. Generated Rules

\begin{tabular}{|c|c|c|c|c|c|}
\hline Rule & IF & THEN & Rule & IF & THEN \\
\hline 1 & G1 OR G2 OR G3 OR G4 & $\mathrm{P} 1$ & 10 & P5 AND G15 & $\mathrm{P} 10$ \\
\hline 2 & K1 AND G5 & $\mathrm{P} 2$ & 11 & K3 AND G16 & P11 \\
\hline 3 & K1 AND G6 & P3 & 12 & P1 AND P11 OR G17 & $\mathrm{P} 12$ \\
\hline 4 & K1 AND P1 OR G7 & P4 & 13 & $\begin{array}{l}\text { P11 AND G18 AND G19 } \\
\text { OR G21 }\end{array}$ & P13 \\
\hline 5 & K2 AND G8 & P5 & 14 & $\begin{array}{l}\text { P13 AND P1 AND G21 } \\
\text { OR G20 }\end{array}$ & P14 \\
\hline 6 & $\begin{array}{l}\text { P5 AND G10 AND G11 OR } \\
\text { G12 OR G13 }\end{array}$ & P6 & 15 & P13 AND G21 OR G22 & P15 \\
\hline 7 & P5 AND G10 OR G12 OR G13 & P7 & 16 & P11 AND G23 AND G24 & P16 \\
\hline 8 & P5 AND G14 & P8 & 17 & $\begin{array}{l}\text { P11 AND G23 AND G24 } \\
\text { OR G25 OR G11 }\end{array}$ & P17 \\
\hline 9 & P8 AND P6 OR P7 & P9 & 18 & P11 AND G16 OR G26 & P18 \\
\hline
\end{tabular}

2. Application of Forward Chaining Method

The expert system used forward chaining; if the premise (if) is true then the conclusion will also be true. Here were the search steps with forward chaining:

Step 1: Ask questions to user

Step 2: Receive input from user as known fact in short-term memory stored in each variable of the question asked

Step 3: Check the rule based on facts on short-term memory using forward chaining method.

Step 4: if rulewas found then conclusion was accommodated in short-term memory, if there is new fact then step one up to step four are repeated. If the rule was not found, give the default output.

Step 5: provide solution 


\subsubsection{Data Analysis using Case Based Reasoning}

Data analysis consist of 8 steps, i.e. building case representation, weighting by experts, local similarity calculation, confidence level calculation, global similarity calculation, highest value selection, revising and storing data in database.

a. Building Case Representation

Case representation was used to identify variables needed. Variables used were weight, height, gender, age, body temperature, and 26 symptoms. Symptoms could be seen in Table 1. Variables were grouped into two kinds, i.e. generic and specific variables. Generic variables were variables that have general properties, such as body height, body weight, body temperature, age, and gender. Specific variables were variables existed only on specific disease.

b. Weighting

Weighting was done by an expert. Weighting is a process of giving weight to each variable. Weighting was calculated using statistical analysis, started by calculating number of variables appeared in target case on training data. Weighting was done by series of iteration. Weighting calculation process using statistical analysis had two prerequisites that must be satisfied. The first was the highest global similarity value should be the comparison value between a testing data and training data matched with doctor's diagnosis data. If the highest global similarity value obtained did not match with doctor's diagnosis, weighting value of system diagnosis should be changed in order to get lower similarity value than global similarity value resulted from doctor's diagnosis. The process of weight changing was adjusted with variable similarity from testing and training data. If variable similarity value was 1 and the weight was high, then the weight must be reduced. If variable similarity value is 0 , then the weight must be added. The second was doing weighting normalization by maintaining the total weight value of all disease to have the same value. In this case, total weight value of all diseases was set to 290 .

c. Local Similarity Calculation

Local similarity calculation was a process of comparing values of symptoms variables between new cases and previous cases. Local similarity calculation for numerical data type was done using equation (1). Local similarity calculation for Boolean data type was done using equation (2).

d. Confidence Value Calculation

Process done in confidence value calculation was calculating the comparison between numbers of variables in new cases and previous cases. The result of confidence value calculation was used to decide whether the new case can continue to the next step of calculation, or must do the reverse step instead. Confidence value of all data having value $<0.75$ (threshold) would be put into reverse process.

e. Global Similarity Calculation

The algorithm used in global similarity process was Nearest Neighbor Similarity using Equation (4), Minkowski Distance Similarity using Equation (5), and Euclidean Distance Similarity using Equation (6). 
f. The Highest Value Selection

The results of the previous step were then processed to get the highest value. The highest value was obtained from the results of global similarity calculation for data 1 and 2. The highest value obtained showing the diagnosis in new cases. Comparation of similarity values using global Nearest Neighbor Similarity, Minkowski Distance Similarity and Euclidean Distance Similarity in data 1 and 2 could be seen in Table 4.

Table 4. The Highest Value Selection.

\begin{tabular}{lllll}
\hline No & CBR & Data 1 & Data 2 & Diagnosis \\
\hline 1 & NNS & 0,49 & 0 & Mild Dehydration Diarrhea \\
2 & MDS & 0.1 & 0 & Mild Dehydration Diarrhea \\
3 & EDS & 0.06 & 0 & Mild Dehydration Diarrhea \\
\hline
\end{tabular}

g. Revision Process

The revision process was carried out only if the confidence level calculation process has a value of $<0.75$. This process was carried out by asking experts for cases that the system cannot diagnose. Determining the system whether can or cannot answer the diagnosis was from the level of confidence. A level of confidence that had a value of $<0.75$ meant that the value did not resemble all data contained in the database.

h. Storing Data in Database

If a new case had been calculated with global similarity and received a diagnosis, the new case data will be entered into the database. The data was then considered to be old data that will be compared with other new data cases to diagnose.

\subsection{System Testing}

System testing was made to be able to determine the level of system accuracy. The results were tested using 600 patient data consisting of 450 training data and 150 testing data. System testing was performed on classifications with forward chaining and classification with CBR. System testing results were described in Table 5.

Table 5. Recapitulation of Test Results.

\begin{tabular}{lc}
\hline \multicolumn{1}{c}{ Method } & Result of Correct Data \\
\hline Forward Chaining & 123 \\
NNS & 120 \\
EDS & 129 \\
MDS & 135 \\
\hline
\end{tabular}

\section{Discussion}

Evaluation of system testing results was done by calculating accuracy, which matched the diagnosis of medical personnel with the results of system diagnosis. Diagnosis using forward chaining was obtained accuracy of $82 \%$, CBR with NNS was obtained accuracy of $80 \%$, EDS of $86 \%$, and MDS of $90 \%$. Optimal accuracy was obtained by diagnosis using CBR with global 
similarity used by MDS. Diagnosis of toddlers using CBR had better accuracy than forward chaining. This was because CBR had a revision process, which justified data that was considered wrong to be repaired by experts and then made a new case[12].

\section{Conclusion}

Based on research and system testing results, it could be concluded that:

1. Diagnosis of toddlers using forward chaining resulted in 18 rules.

2. The accuracy obtained was $82 \%$ for forward chaining, diagnoses of toddlers using CBR obtained $80 \%$ accuracy for NNS, $86 \%$ for EDS, and 90\% for MDS.The most optimal accuracy was accuracy using CBRwith global similarity used by MDS of $90 \%$, this is because CBR has a revision process.

\section{References}

[1] N. H. Perlroth and C. W. Castelo Branco, "Current knowledge of environmental exposure in children during the sensitive developmental periods," J. Pediatr. (Rio. J)., vol. 93, no. 1, pp. 17-27, 2017.

[2] M. Garenne, C. Ronsmans, and H. Campbell, "The magnitude of mortality from acute respiratory infections in children under 5 years in developing countries.," World Health Stat. Q., vol. 45, no. 23, pp. 180-191, 1992.

[3] Ministry of National Development, Report on The Achievement of The Millennium Development Goals Indonesia 2010. 2010.

[4] K. K. R. Indonesia, Pedoman Penyelenggaraan Manajemen Trpadau Balita Sakit Berbasis Masyarakat (MTBS-M). 2014.

[5] I. Subakti, "Sistem Pendukung Keputusan Jurusan Teknik Informatika Fakultas Teknologi Informasi Institut Teknologi Sepuluh Nopember Surabaya,” J. Ilm. Teknol. Inf. Inst. Teknol. Sepuluh Nop., vol. 4, no. Management Support System, pp. 5-9, 2013.

[6] J. P. Jiawei Han, Micheline Kamber, Data Mining Concepts and Techniques. 2012.

[7] C. Fiarni, A. S. Gunawan, Ricky, H. Maharani, and H. Kurniawan, "Automated Scheduling System for Thesis and Project Presentation Using Forward Chaining Method with Dynamic Allocation Resources," Procedia Comput. Sci., vol. 72, pp. 209-216, 2015.

[8] D. S. Pinurbo and E. Ariyanto, "Implementasi Metode Forward Chaining Untuk Analisa Pendeteksian Dini Penyakit Diabetes Mellitus," Inst. Teknol. Telkom Bandung, 2012.

[9] Y. K. P. Tjumoko, A. Sukmaaji, and J. Lemantara, "Aplikasi Sistem Pakar Diagnosis Penyakit Menular Pada Balita Dengan Metode Forward Chaining," no. 1, pp. 1-8, 2008.

[10] M. Ochab and W. Wajs, "Expert system supporting an early prediction of the bronchopulmonary dysplasia," Comput. Biol. Med., vol. 69, pp. 236-244, 2016.

[11] H. Ahn and K. jae Kim, "Bankruptcy prediction modeling with hybrid case-based reasoning and genetic algorithms approach," Appl. Soft Comput. J., vol. 9, no. 2, pp. 599-607, 2009.

[12] S. C. K. S. Sankar K. Pal, Foundations of Soft Case-Based Reasoning, vol. 7, no. 1. 1993.

[13] E. Wahyudi and S. Hartati, "Case-Based Reasoning untuk Diagnosis Penyakit Jantung," IJCCS (Indonesian J. Comput. Cybern. Syst., vol. 11, no. 1, p. 1, 2017. 